http://dx.doi.org/10.30681/23588403v13i0214

\title{
A POLÍTICA LINGUÍSTICA NOS GAMES
}

Data de recebimento: $13 / 03 / 2020$

Aceite: 28/04/2020

\section{Anna Karoliny dos Santos SILVA (UFSC) ${ }^{1}$} Silvia Maria CANTELI (UFSC) ${ }^{2}$

\begin{abstract}
Resumo: O presente artigo tem como objetivo a discussão a respeito da linguagem e identidade gamer como política linguística. Essa questão é abordada por meio de pesquisas e coletas de dados que visam identificar sua linguagem e identidade gamer, relatando e expondo alguns dados sobre linguagem e vivência gamer. Para tanto, observou-se que os discursos de gamers envolvem questões sobre machismos e ambientes tóxicos, dos quais são fomentados por um sistema de marketing mundial focalizado mais em vender a imagem, vulgo identidade gamer, do que em inserir os games como um ambiente de lazer e de comunicação e interação global. O Brasil tornou-se um dos maiores polos de tecnologia em games do mundo e com esse crescimento surgiram embates de questões sociais e culturais. O estudo de campo foi analisado neste país, especificamente na região de Florianópolis/SC, pois atualmente a cidade de Florianópolis também está na lista dos maiores polos tecnológicos do Brasil, conhecida por ser a capital da inovação e como a segunda cidade mais empreendedora desse país.
\end{abstract}

Palavras-chave: Política Linguística. Gamer. Inglês. Identidade. Cultura.

Abstract: This article aims to discuss about language and gamer identity as a language policy. Its purpose is identify your language and gamer identity through research and data collection, reporting and exposing some data on gamer language and experience. To this end, it was observed that gamers' speeches involve questions about chauvinism and toxic environments, which are fostered by a worldwide marketing system focused on selling the image, commonly known as gamer identity, than to insert games as a leisure environment. and global communication and interaction. Brazil has become one of the largest centers of gaming technology in the world, and with this growth came clashes of social and cultural issues. The field study was analyzed in this country, specifically in the region of Florianópolis / SC, because currently the city of Florianópolis is also on the list of the largest technological centers in Brazil, known for being the innovation capital and as the second most enterprising city in the country. Keywords: Linguistic Policy. Gamer. English. Identity. Culture.

\section{Introdução}

\footnotetext{
${ }^{1}$ Estudante de bacharelado em Letras Língua Portuguesa e Literaturas, na Universidade Federal de Santa Catarina - UFSC e estudante no curso de Marketing Social, no Serviço Nacional de Aprendizagem Comercial SENAC.

${ }^{2}$ Estudante de licenciatura em Letras Língua Portuguesa e Literaturas, na Universidade Federal de Santa Catarina - UFSC; graduada em Letras bacharelado em Língua Inglesa com habilitação em Secretariado Bilíngue em Letras pela Pontifícia Universidade Católica de Campinas - PUCCAMP e Pós-graduada em Metodologia de Ensino de Língua Portuguesa e Estrangeira pelo Centro Universitário Internacional - UNINTER.
} 
A presente pesquisa, realizada por meio de método exploratório, tem como propósito abordar questões de linguagem, identidade e cultura gamer sob aspectos das políticas linguísticas.

Em um primeiro momento apresentamos os aspectos da pesquisa de campo que abrange um formulário para coleta de dados respondido por trinta (30) pessoas e uma entrevista realizada por meio de gravação de voz por uma pessoa de 26 anos, do sexo feminino, gamer há mais de 15 anos, estudante de Sistemas e Full Support Analyst no setor de TI numa empresa de energias renováveis.

A coleta de dados foi desenvolvida por meio de um formulário no Google Drive, abordando questões como "Você se auto qualifica como gamer?", "Comente com suas palavras a respeito da cultura Gamer", "Comente e exemplifique a respeito da linguagem Gamer/Cite alguns termos gamers", "Você sabe falar inglês?/Se sim, qual sua fluência?", "Relate como era sua experiência dentro dos games tendo o inglês como meio de comunicação (Tanto quando em comunicação com outros jogadores, quanto quando o jogo [RPG por exemplo] era inteiramente em inglês)", "Como o game refletiu para seu aprendizado e contato com a língua?".

A pesquisa teve como público alvo pessoas que já jogaram quaisquer tipos de games e eSports ${ }^{3}$; pessoas que consideram possuir uma identidade gamer e apreciadores da cultura gamer.

Na primeira fase da pesquisa de campo, utilizamos perguntas para comprovar se existe de fato uma cultura gamer; se as pessoas que responderam ao formulário reconhecem essa cultura e identificam o inglês como meio de comunicação global e por fim analisar questões socioculturais.

Essa primeira fase, coleta de dados, serviu de motivação para realizarmos uma segunda fase, a entrevista gravada. Nessa segunda fase a entrevistada reportou que possui nível avançado de inglês, costuma jogar sempre em inglês e joga tanto com brasileiros quanto com estrangeiros. Um dado importante levantado na entrevista foi que a entrevistada teve seu primeiro contato com o idioma inglês por meio dos jogos e que o idioma presente no jogo força a aprender a língua inglesa. Outro dado importante mencionado é que no mundo gamer existem muitas gírias e que não é uma identidade gamer, mas uma cultura de marketing. A entrevistada comenta que dentro dessa cultura gamer ela já sofreu assédio por ser mulher e por isso prefere jogar usando apelido masculino.

\footnotetext{
${ }^{3}$ Esportes eletrônicos
} 
Para possibilitar elucidar algumas questões organizamos esse artigo em seis tópicos: Introdução, Games, Língua dos Games, Identidade Gamer, Cultura Gamer e Considerações Finais.

\subsection{DADOS DA PESQUISA DE CAMPO: PERFIL DE JOGADORES E SEUS HÁBITOS}

A pesquisa ${ }^{4}$ aponta que a faixa etária dos que responderam a pesquisa estão entre $16 \mathrm{e}$ 49 anos, conforme demonstra a Figura 1. O gênero masculino é predominante representando $73,4 \%$, o gênero feminino aparece com $26,7 \%$.

Figura 1- Idade

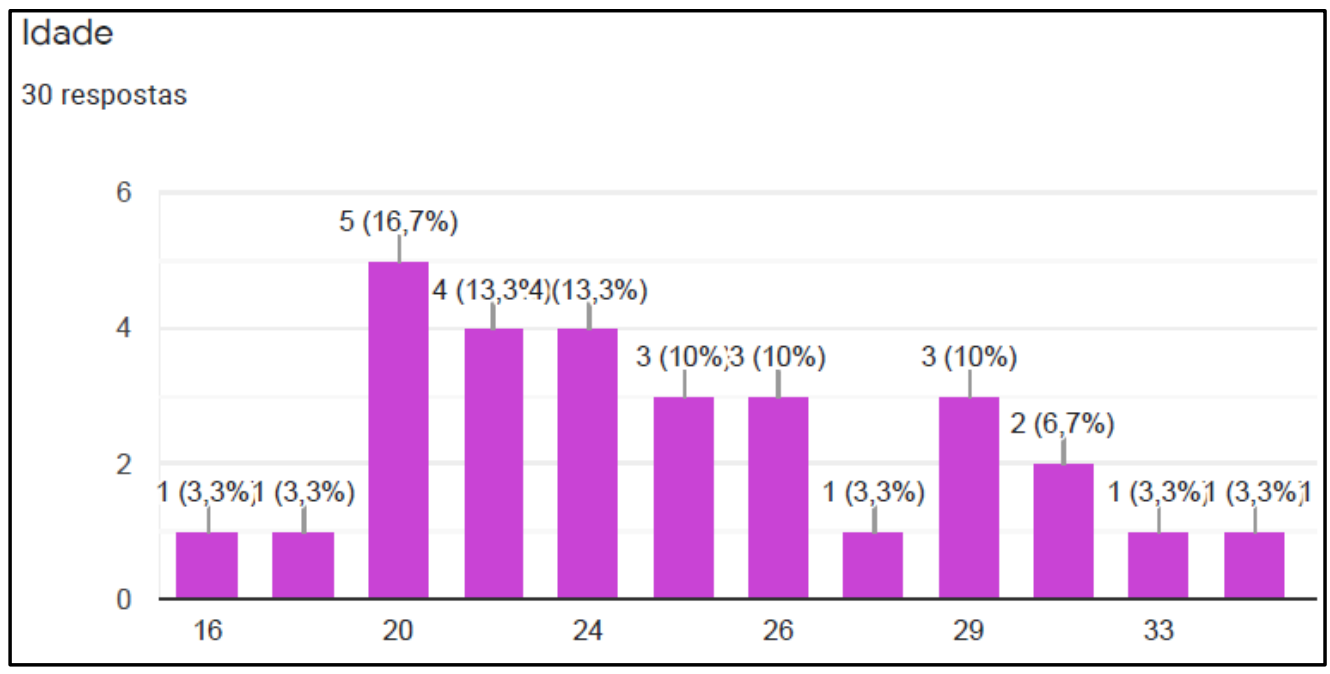

Fonte: do Autor (2019).

Em relação às profissões percebe-se no gráfico da Figura 2 que são diversas, destacando $26.7 \%$ que se classificam como estudantes.

Figura 2 - Profissão

\footnotetext{
${ }^{4}$ Fonte: gráfico gerado pelo Formulário do google drive Pesquisa de Campo - Cultura Gamer e Políticas Culturais e Linguística, com base nos dados das respostas dos pesquisados.
} 


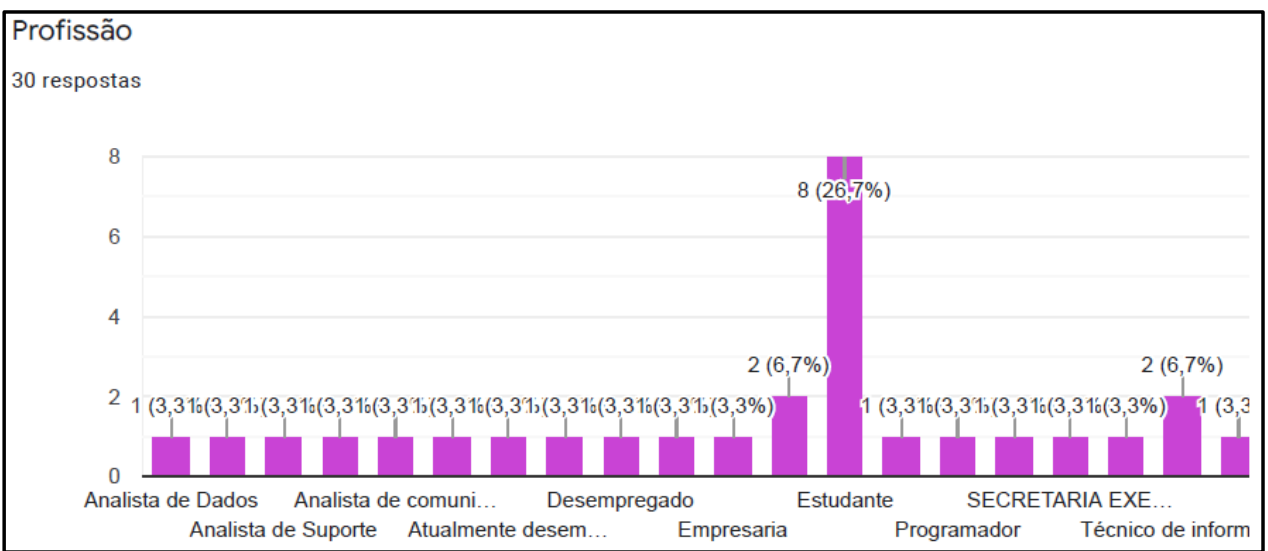

Fonte: do Autor (2019)

O gráfico da pesquisa (Figura 3), destaca que 53, 3\% consideram-se gamers e 26,7\% jogam, mas não se identificam gamers. A maioria deles informaram jogar games há mais de dez anos e muitos deles começaram na infância, sendo apenas sete as exceções. Um fato que chama a atenção é que das oito pessoas que informaram não se identificar gamers é que quatro delas jogam há mais de vinte anos, três há mais de 10 anos e uma há dez anos.

Figura 3 - Gamer

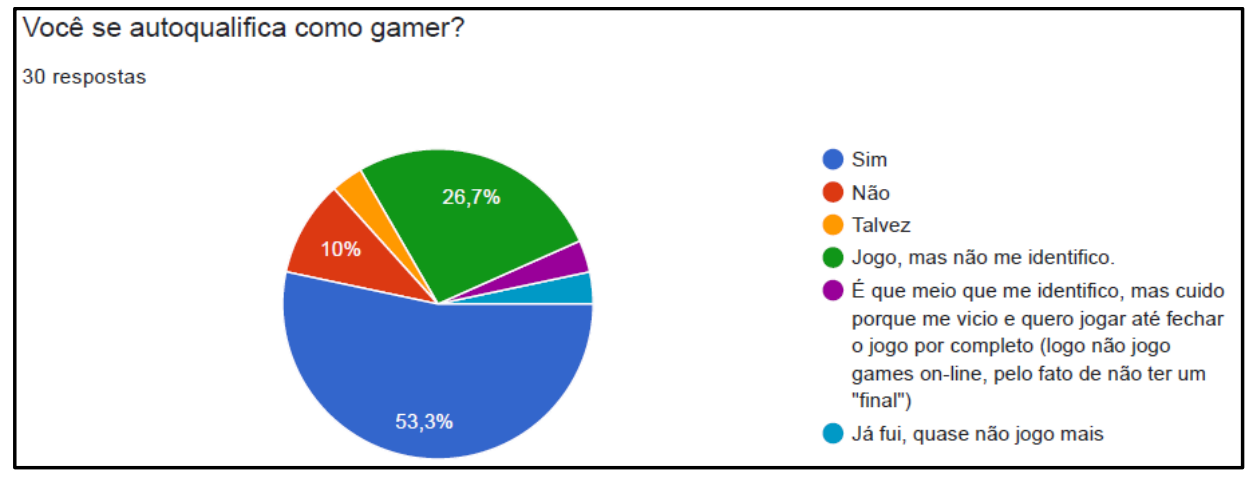

Fonte: do Autor (2019).

A pesquisa revela que daqueles que se consideram gamers $50 \%$ falam inglês, sendo que $30 \%$ deles têm nível intermediário e $26,7 \%$ são fluentes nesse idioma, conforme demonstrado nas Figuras 4 e 5.

Figura 4 -Idioma inglês 


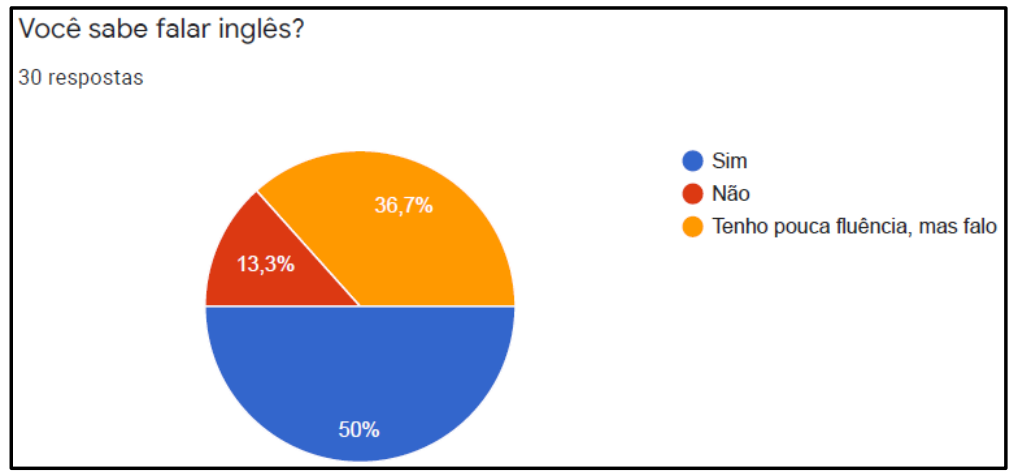

Fonte: do Autor (2019).

Figura 5 - Grau de fluência em inglês

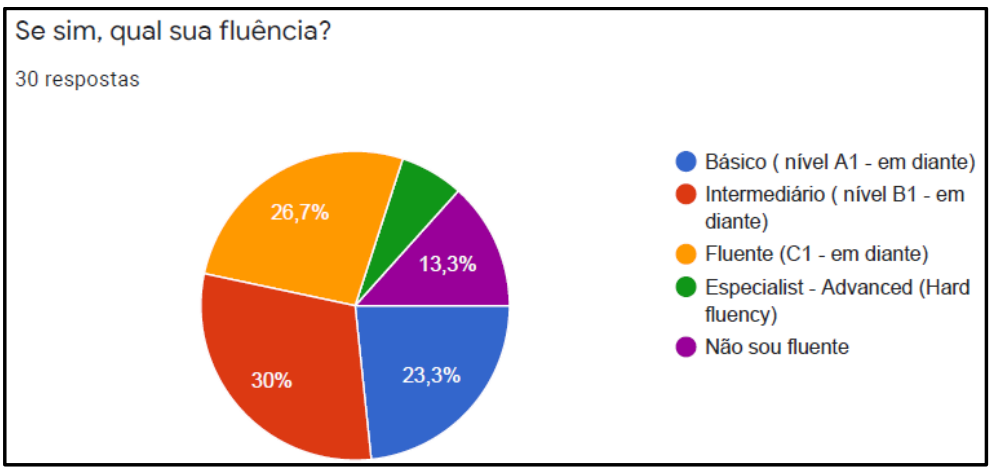

Fonte: do Autor (2019).

Os relatos dos comentários da pesquisa evidenciam que o game é um dos meios para apoio ao aprendizado de inglês, pois existem jogos menos intuitivos que exigem o domínio da língua inglesa e com isso influencia positivamente o jogador para a busca do conhecimento nesse idioma, bem como o motiva a uma constante prática. Segundo os comentários houve caso em que o primeiro contato com a língua inglesa foi através dos games, outro caso comentado foi de que para ter contato com outros usuários é preciso subir de nível na língua. Além disso, muitos comentaram terem aprendido dialetos, gírias e diálogos no idioma inglês com a prática nos games.

A pesquisa, conforme Figura 6, confirma que $80 \%$ dos participantes consideram que a plataforma gamer deveria ser mais valorizada como ferramenta de apoio ao aprendizado da língua inglesa. Um dos comentários na pesquisa é de que os jogos ajudam desenvolver habilidades como a percepção, estratégia e conhecimento em outras línguas.

Figura 6 - Plataforma game para aprendizado de inglês 


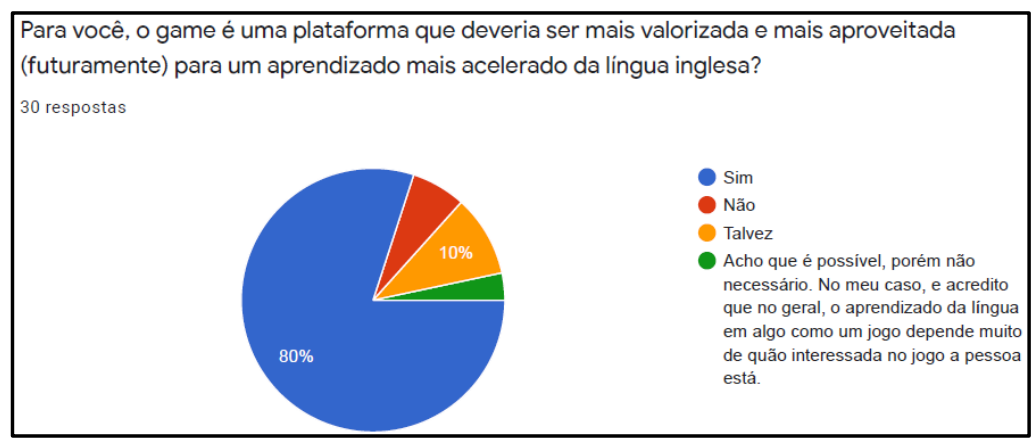

Fonte: do Autor (2019).

Em relação ao hábito de jogar a maioria informou jogar games desde a infância e entre os tipos de jogos destacam-se o Counter Strike Global Offensive com 53 3\%, League of Legends e World Warcraft com 43,3\%, Hearthstone: Heroes of Warcraft e Overwatch com 36,7\%, conforme pode ser constatado na Figura 7.

Figura 7 - Tipos de Jogos mais utilizados

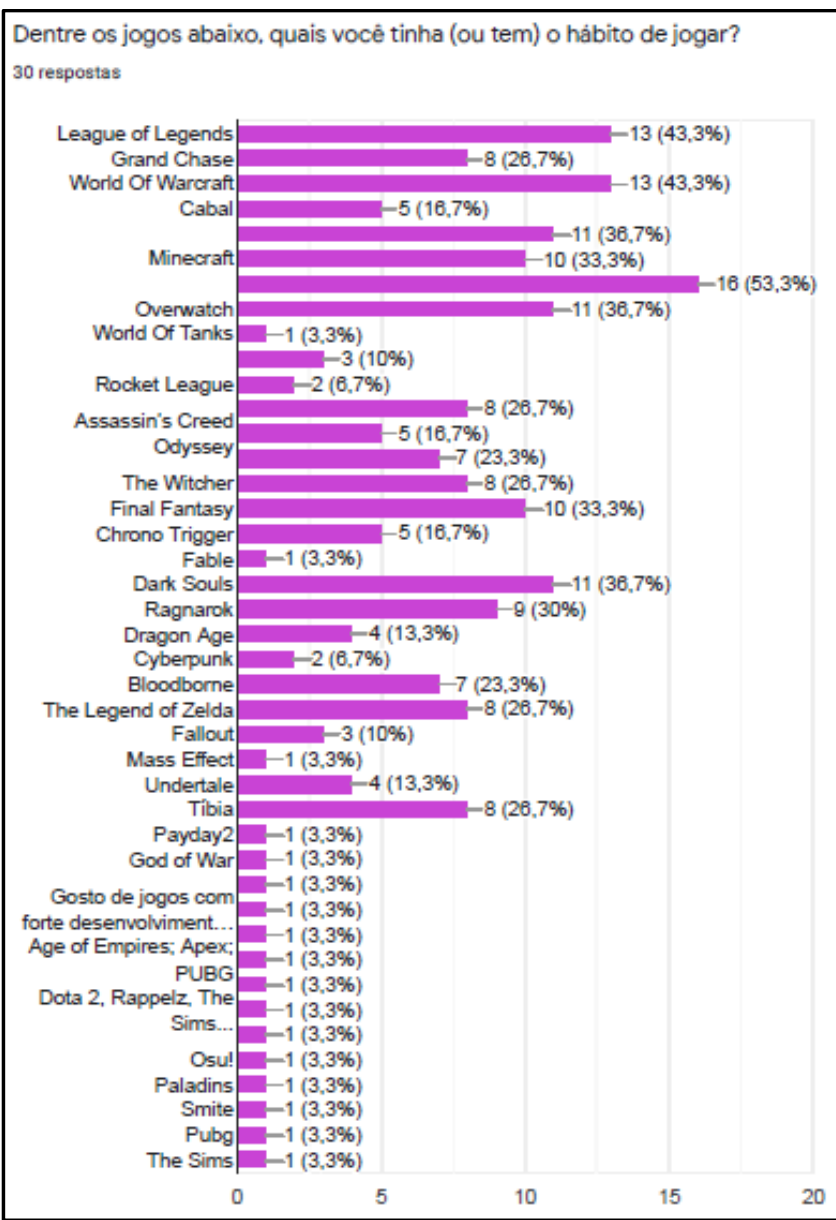

Fonte: do Autor (2019).

\section{GAMES}


Popularmente o game é definido como um processo lúdico que possui uma "intenção" que leva a um resultado, porém esta é uma definição um tanto quanto superficial. No caso dos jogos eletrônicos interativos ou game interativo, trata-se de um processo que envolve seguir uma lógica em que se você faz algo dentro do game ou você ganha ou você perde, englobando diversas habilidades, tempo para praticar, estratégias e decisões.

O game é de origem cultural antiga; não como o conhecemos hodiernamente de modo tecnológico, mas a "intenção" de jogar. Há, contudo, na narrativa dos jogos uma intenção por trás do gameplay ${ }^{5}$. Por exemplo, numa partida de futebol qual é a intenção? Ganhar. Mas de que modo? De que forma precisa desdobrar seu raciocínio lógico para poder desenvolver-se dentro do jogo e alcançar o objetivo final? Precisa mover-se, analisar perímetro, capacidade e perfil de cada jogador, promover estratégias de rota, de ataque e de defesa. Ou seja, o game produz a ideia de que precisa fazer "algo". Logo notamos que o game se torna algo desafiador pois inserimo-nos na narrativa do jogo e começamos a pensar estrategicamente de acordo com as regras que são condicionadas.

(...) Cada um desses games apresenta ao jogador uma série de desafios à medida que o game progride e um objetivo em mente, seja a vitória em um cenário, acúmulo de dinheiro, atingir o próximo nível, derrotar o chefão ou conseguir uma pontuação alta" (SHUYTEMA, 2008, p.7)

Os games também podem ser definidos por serem jogos eletrônicos, que envolvem uma série de processos, estratégias e regras, por meio do qual um gamer interage com uma máquina, conhecida por IA ${ }^{6}$, ou com outro gamer. Na definição de Santaella (2004), "games são híbridos porque envolvem programação, roteiro de navegação, design de interface, técnicas de animação, usabilidade".

Para melhor situar o "mundo gamer”, postulamos uma definição mais abrangente sobre jogos eletrônicos interativos a saber:

Um game é uma atividade lúdica composta por uma série de ações e decisões, limitado por regras e pelo universo do game, que resultam em uma condição final. As regras e o universo do game são apresentados por meios eletrônicos e controlados por um programa digital. As regras e o universo do game existem para proporcionar uma estrutura e um contexto para as ações de um jogador. As regras também existem para criar situações interessantes com o objetivo de desafiar e se contrapor com o jogador. As ações do jogador, suas decisões, escolhas e oportunidades, na verdade, sua jornada, tudo isso compõe a "alma do game. A riqueza do contexto, o desafio, a emoção e a diversão da jornada de um jogador, e não simplesmente a obtenção da condição final, é que determina o sucesso do game. "(SCHUYTEMA, 2008, p.7)

\footnotetext{
${ }^{5}$ Gameplay é o que acontece entre o início e o final de um game - desde o momento em que você aprende quais são os objetivos até atingir a vitória ou o fracasso no final" (SHUYTEMA, 2008, p. 7).

${ }^{6}$ Inteligência Artificial.
} 
Em relação ao surgimento dos games, em sua pesquisa Zille (2012) relata que os primeiros games criados foram o Tennis for Two e o Spacewar. Esse primeiro game foi desenvolvido em 1958, por Willian Higinbotham, no laboratório americano de pesquisas nucleares, Brookhaven National Laborator, e tratava-se de um ponto luminoso movendo-se na tela de um osciloscópio, e dois jogadores, através de potenciômetros, controlavam cada qual uma "barra" que, deslocando-se verticalmente, atuavam como obstáculos na tela, impedindo o ponto luminoso que simulava uma bola. O segundo, Spacewar, foi criado em 1962, por Steve Russel, no MIT, e pode ser considerado de fato como sendo o primeiro game no formato que se vê hoje.

Uma importante inovação no jogo, surgiu em 1970 com os jogos multiplayers online denominados $M U D$ 's, um jogo ambientado em mundos fantásticos onde vários jogadores interagem simultaneamente. É a partir desse momento que os jogadores, segundo Zille (2012), interpretam seus personagens, se comunicam entre si e participam das aventuras e missões apresentadas. Nesse momento, esse sistema de jogo cria diversas comunidades MUD's e assim começa a surgir uma nova cultura gamer.

Ressaltamos também que quando se trata de cultura é importante perceber as diferenças existentes entre os jogos tradicionais e os jogos eletrônicos. Para Santaella (2004):

Uma característica fundamental de todo e qualquer jogo, inclusive dos tradicionais,
não-eletrônicos, encontra-se na sua natureza participativa. Sem a participação ativa e
concentrada do jogador, não há jogo. Mantendo essa característica básica e comum a
qualquer jogo, a grande distinção do jogo eletrônico em relação a quaisquer outros
encontra-se, antes de tudo, na interatividade e na imersão. (SANTAELLA, 2004, p.2)

\subsection{EXEMPLOS DE JOGOS ELETRÔNICOS}

Nesta subseção será exemplificado algumas modalidades de jogos atuais globalmente reconhecidos no universo dos games, tais como: RPG e MOBA.

\subsubsection{RPG}

O sistema de jogos RPG é o mais comum entre o universo gamer. Sua sigla em inglês, significa role-playing game e é um gênero de jogo do qual os jogadores assumem o papel de personagens imaginários em um mundo fictício. Podem ser jogados de diversas formas e as mais comuns são através de atuação literal, na qual os jogadores agem, falam e se vestem como seus personagens, e o RPG de mesa (tabuleiro), que foi primeiro modo criado para jogar RPG. 
Em qualquer modalidade de RPG, as histórias são guiadas por um jogador denominado "mestre", que conduz a história, descreve os cenários, controla os inimigos que outros jogadores enfrentam, e entre outros papéis. Enquanto isso, os outros jogadores tomam suas decisões de forma "livre" conforme as situações são narradas pelo mestre (há sempre um condicionamento do qual obriga você a agir; "ou você faz isso" ou "você faz aquilo").

\subsubsection{MOBA}

Os games MOBA são atualmente os games mais jogados no mundo dos games e dos eSports. O significado de MOBA em inglês é Multiplayer Online Battle Arena e é uma modalidade de jogos eletrônicos onde 2 times enfrentam-se num campo de batalha (geralmente 5 jogadores versus 5 jogadores) com o objetivo de destruir a base inimiga.

Nesta modalidade cada jogador controla um personagem com características diferentes dos outros, o que faz o MOBA também ser um jogo de estratégia. Cada champ (herói do jogo; personagem que você escolhe jogar) possui habilidades e classes diferenciadas, como: magos, assassinos, atiradores, bruxos, soldados, suportes, etc.

Para finalizar este capítulo podemos dizer que o mundo dos games engloba aspectos de língua, identidade e cultura, pois os jogos vão além dos muros, ultrapassam fronteiras locais e culturais. Abordaremos cada um desses aspectos adiante.

\section{LÍNGUA DOS GAMES}

Dentro do universo dos games multiplayers é possível unir pessoas de qualquer localidade do mundo, do qual este envolvimento global resulta num amplo acesso cultural. $\mathrm{O}$ game quando inserido no universo cultural de cada regionalidade torna mais profunda a experiência do gamer a ponto dele precisar desdobrar-se para entender um idioma considerado "universal" e a entender as ideias e intenções do multiplayer para que consiga proceder com os objetivos do game, além do fato de que através deste acesso é possível relacionar-se de variadas formas e a conhecer os conceitos e ideologias socioculturais de cada jogador. Ou seja, o gamer possui acesso virtual, indireto, ao universo cultural daquela pessoa, daquele outro gamer (como vivem, como se comunicam/relacionam, quais seus conceitos políticos de comunicação e como são estabelecidas, como é sua cultura, entre outros), pois o game também é utilizado como meio de comunicação global e torna-se um ciberespaço para chats. 
Como estes jogos multiplayers são deliberadamente internacionais e produzidos essencialmente com dublagem e narração em inglês, atualmente foi desenvolvida uma linguagem gamer que é inserida nas plataformas comunicacionais do Brasil, resultado este de uma longa tentativa de comunicação digital nos games. Portanto, através da presente pesquisa de campo, também é possível chegar numa conclusão de que há uma tendência natural do brasileiro em apropriar-se da língua inglesa e configurá-la em um abrasileiramento; pega-se uma palavra-ideia e a converte ou assimila-se semântica, fonética e graficamente para a língua portuguesa brasileira.

A pesquisa de campo, conforme observamos nos comentários, revelou que a linguagem gamer é específica com seus neologismos, jargões e gírias e por isso é preciso estar inserido nessa cultura para acompanhar alguns termos como, por exemplo, entre jogadores do mesmo gênero que tem sua singularidade nos termos utilizados.

Nos jogos online onde normalmente tem interação com outros jogadores são usadas muitas palavras abreviadas e algumas específicas daquele jogo. Além disso a linguagem varia de jogo para jogo, mas é predominantemente em inglês, possui adaptações de palavras em inglês para o português e algumas gírias inventadas pela própria comunidade.

Um dos fatores que mais influencia o uso das palavras em inglês é que a maioria dos jogos mais famosos começaram em servidores nesse idioma e por isso é necessária a adaptação para se inserir nessa cultura. Além do mais, muitos termos necessários para entender e poder jogar não existem em dicionário, assim é preciso criar termos próprios para poder exemplificar objetivos e metas do jogo específico.

Assim, há várias termos e palavras específicas de cada jogo que são adaptadas de inglês para o português com a finalidade de facilitar a comunicação, pois a maioria dos jogos não possuem tradução. Por exemplo, no jogo League of Legends quando selecionamos um personagem dizemos que "pickamos", palavra derivada de "pick" e que significa escolha.

$\mathrm{Na}$ linguagem utilizada existem jargões próprios derivados e abrasileirados de termos em inglês, tal como "gankar" de "gank"/"ganking", "camperar" de "camper"(ing), "snipar/esnaipar" de "sniper" (ping). Além disso, é comum termos diretamente do inglês, como "kill" significando abate, “GG” abreviação de "good game", “top/mid/bot” entendido como rota superior, meio e inferior, respectivamente.

Em alguns casos é criado gírias em português nascidas de situações não relacionadas a termos estrangeiros, como "lambida" (abater em combate próximo em jogos de tiro), "morando" (ficar muito tempo em um único local), "deitar" (abater). 
A linguagem Gamer auxilia na rapidez e entendimento entre os jogadores durante uma partida, facilitando a agilidade nas ações.

Para tanto, logo abaixo foi inserido um quadro com exemplos comuns de "Gírias e Apropriações":

Quadro 1 - Gírias e apropriações "abrasileiradas"

\begin{tabular}{|c|c|c|}
\hline Termos & Significado & Quando é Utilizado \\
\hline$A F K$ & Away From Keyboard & $\begin{array}{l}\text { Quando está jogando e vai dar uma saída } \\
\text { rápida }\end{array}$ \\
\hline Bot & IA - Inteligência Artificial & $\begin{array}{l}\text { Quando você quer treinar e montar } \\
\text { partidas privadas contra bots antes de ir } \\
\text { para o online. } \\
\text { Ou refere-se ao caminho da "lane" que } \\
\text { você quer jogar, por exemplo: nos jogos } \\
\text { do League of Legends você precisa tem } \\
\text { acesso a pelo menos } 3 \text { caminhos gerais } \\
\text { para as batalhas, chamados: top/topo, } \\
\text { mid/meio e bot/baixo. }\end{array}$ \\
\hline Buff & Melhoria/ Upgrade & $\begin{array}{l}\text { Quando o personagem, normalmente de } \\
\text { jogos de FPS tem alguma habilidade } \\
\text { melhorada. }\end{array}$ \\
\hline Bug (bugar) & Erro/ Falha técnica & $\begin{array}{l}\text { Muito usado para falar que o jogo está } \\
\text { acontecendo coisas inusitadas como } \\
\text { rostos deformados, entre outros. }\end{array}$ \\
\hline Camper & $\begin{array}{l}\text { Aquele player que fica parado em pontos } \\
\text { estratégicos do mapa esperando os } \\
\text { inimigos passarem. }\end{array}$ & $\begin{array}{l}\text { Usado para avisar que tem um sniper } \\
\text { próximo ou um inimigo escondido em } \\
\text { algum lugar do mapa. }\end{array}$ \\
\hline Char & Character & $\begin{array}{l}\text { É o seu personagem. Em jogos de RPG e } \\
\text { MMO, você precisa desenvolver seu } \\
\text { próprio char. }\end{array}$ \\
\hline Cheat & Trapaça & $\begin{array}{l}\text { Quando o jogador usa algum tipo de } \\
\text { código ou programa para se dar bem no } \\
\text { jogo trapaceando. }\end{array}$ \\
\hline \multirow[t]{2}{*}{ Cover } & \multirow[t]{2}{*}{ Cobertura } & $\begin{array}{l}\text { Quando você abaixa para se proteger de } \\
\text { dano inimigo. }\end{array}$ \\
\hline & & $\begin{array}{l}\text { Também é usado o "cover me" quando o } \\
\text { aliado pede cobertura. }\end{array}$ \\
\hline Drop (dropar) & Jogar no chão & $\begin{array}{l}\text { Quando você quer entregar algum item } \\
\text { que não te serve mais ou que um amigo } \\
\text { necessita. }\end{array}$ \\
\hline
\end{tabular}




\begin{tabular}{|c|c|c|}
\hline Farm (Farmar) & Acumular objeto & $\begin{array}{l}\text { Usado no RPG, quando você precisa } \\
\text { acumular um item e só consegue isso } \\
\text { com um processo repetitivo. }\end{array}$ \\
\hline$G G$ & Good Game & $\begin{array}{l}\text { Quando seu time termina ganhando e } \\
\text { teve uma boa partida. Também é usado } \\
\text { "GG Easy" para falar que a partida foi } \\
\text { muito fácil. }\end{array}$ \\
\hline Headshot & Tiro na cabeça & $\begin{array}{l}\text { Normalmente é usado quando o tiro é } \\
\text { certeiro. }\end{array}$ \\
\hline$I D K$ & I don't know & $\begin{array}{l}\text { Usado quando você não faz ideia do que } \\
\text { o seu aliado está falando ou pedindo. }\end{array}$ \\
\hline$K S$ & Kill Stealer & $\begin{array}{l}\text { Gíria usada para o famoso "ladrão de } \\
\text { kill" }\end{array}$ \\
\hline Lag/ jogo lagado & $\begin{array}{l}\text { Quando o jogo está lento, travando } \\
\text { bastante. }\end{array}$ & $\begin{array}{l}\text { É usado para avisar aos outros jogadores } \\
\text { que a sua internet está ruim ou porque } \\
\text { você caiu em um servidor gringo. }\end{array}$ \\
\hline$L O L$ & Laughing out loud & $\begin{array}{l}\text { Quando algo muito engraçado aconteceu } \\
\text { e você quer interagir sobre com os outros } \\
\text { jogadores. }\end{array}$ \\
\hline Newbie & Novato & $\begin{array}{l}\text { O jogador que não conhece nada do jogo, } \\
\text { está aprendendo os comandos ainda. }\end{array}$ \\
\hline Noob & Jogador ruim & $\begin{array}{l}\text { Quando o jogador já é um veterano e } \\
\text { continua ruim. }\end{array}$ \\
\hline$N P$ & No problem & $\begin{array}{l}\text { Usado mais em chats para dizer que não } \\
\text { tem problema. }\end{array}$ \\
\hline Owned & Humilhação & $\begin{array}{l}\text { Quando se humilha o adversário, quando } \\
\text { se está com vantagem sobre ele }\end{array}$ \\
\hline Pay to Win & Pagar para vencer & $\begin{array}{l}\text { É uma técnica usada por algumas } \\
\text { desenvolvedoras para ganhar dinheiro e } \\
\text { assim privilegiar os jogadores que têm } \\
\text { dinheiro para investir. Quanto mais } \\
\text { investem, mais poderoso aquele jogador } \\
\text { é, tendo vantagem sob os demais. }\end{array}$ \\
\hline Ping & $\begin{array}{l}\text { Termo de medida da latência da internet. } \\
\text { Quanto maior o ping, pior está a internet. }\end{array}$ & $\begin{array}{l}\text { É usado para comunicar qual a } \\
\text { velocidade da sua internet naquele } \\
\text { momento. }\end{array}$ \\
\hline$P V P$ & Player vs player & $\begin{array}{l}\text { Usado somente em jogos online, você } \\
\text { utiliza quando entra em confronto com } \\
\text { outro player. }\end{array}$ \\
\hline$R P G$ & Role Playing Game & $\begin{array}{l}\text { Um estilo de jogo onde não há } \\
\text { ganhadores e nem perdedores. }\end{array}$ \\
\hline
\end{tabular}




\begin{tabular}{|l|l|l|}
\hline Rushar & Metralhar & $\begin{array}{l}\text { Usado para falar que algum gamer está } \\
\text { atirando para qualquer lado. }\end{array}$ \\
\hline Skill & Habilidade & $\begin{array}{l}\text { Usado para categorizar habilidade de } \\
\text { classes ou personagens específicos. }\end{array}$ \\
\hline Skin & Pele/ Roupa/ Vestuário & $\begin{array}{l}\text { É a parte estética do personagem. Uma } \\
\text { skin não influencia na melhoria das } \\
\text { habilidades. }\end{array}$ \\
\hline Ult (ultar) & Ultimate & $\begin{array}{l}\text { Alguns games possuem um poder } \\
\text { máximo que é carregado no decorrer do } \\
\text { jogo. }\end{array}$ \\
\hline
\end{tabular}

Fonte: SEVEN IDIOMAS (2015); Acervo Pessoal (2019).

É importante citar que por meio dessa linguagem os gamers fecham-se numa comunidade, sendo assim, limitam-se em manter uma convenção separatista de "classes" em que "esse" ou "aquele" possui um conhecimento mais elevado da língua inglesa, ou como Silva (2013) também denota: "Socialmente, a proficiência em uma língua é percebida como um símbolo de status, de poder, de pertencimento a grupos específicos”. Incluindo também a capacidade de raciocinar melhor e a elaborar as melhores estratégias de jogo (não esquecendo da própria guerra de egos que sempre existiram dentro dos jogos multiplayers). É, também nesse caso, que observando o grau de conhecimento da linguagem gamer, é possível entender o nível de imersão do qual uma pessoa está inserida no universo gamer.

\section{IDENTIDADE GAMER - GAMER AS A LIFESTYLE}

Antes de iniciar a abordagem da identidade gamer, trataremos da questão sobre identidade cultural. Para isso, tomamos por base o livro "A identidade cultural na pósmodernidade" de Stuart Hall (2006), pois os gamers surgiram nesse período.

No final do século XX já era percebida por Hall um movimento de transformação de identidade pessoal e cultural da sociedade moderna e desse movimento emergia "um novo sujeito". Em resumo, o indivíduo antes do século XX tinha uma identidade unificada e estável e ao adentrar a pós-modernidade devido as mudanças globais não era mais o mesmo e estava despontando um "novo sujeito". Hall (2006) afirma que "de acordo com alguns teóricos, o "'sujeito" do Iluminismo, visto como tendo uma identidade fixa e estável, foi descentrado, resultando nas identidades abertas, contraditórias, inacabadas, fragmentadas, do sujeito pósmoderno". 
Mas, o que realmente é ser gamer? A Identidade game tem um fator condicionante? De acordo com a entrevistada da presente pesquisa de campo, você se torna gamer sob influência da indústria cultural dos games, e você não nasce gamer. Ou seja, você recebe essa identidade. Olha, analisa, vê que é um universo que pode lhe oferecer liberdade dentro de um mundo de fantasias (e que pode suprir as suas próprias e seus próprios sonhos), e então você se insere no universo.

Neste sentido de pertencimento, Shohamy nos elucida que:

[...] a língua é utilizada para expressar pertencimento a um determinado grupo ("nós/eles), para demonstrar inclusão ou exclusão, para determinar lealdade ou patriotismo, para indicar status econômico ("tenho/não tenho") e para a classificação de pessoas e identidades individuais. Além disso, a língua é utilizada como uma forma de controle, ao se impor o uso de uma língua determinados modos (correto, autêntico, native-like, gramatical, tec.) ou mesmo ao se controlar o direito de utilizá-la" (SHOHAMY, 2006, p.XV, apud Silva, 2013, p.310)

Há, no entanto, uma supremacia de marketing gamer que age de forma ludibriosa para que você se torne um gamer. Por exemplo, uma das maiores (senão a maior) empresas que colaboraram para que se estabeleça um perfil gamer e de ciberatletas e/ou jogadores é a RIOT, produtora de League of Legends. Assim, percebe-se que a identidade gamer é singular.

Para finalizar concordamos com Zille (2012) que:

O game extrapolou em muito a ideia de experimento, ou mesmo de puro jogo, para se posicionar com uma subcultura (GAME Cultura). Sob essa perspectiva, o game produz um conjunto de signos capazes de atuar em vários aspectos da vida, seja em comportamentos, valores, criações e mesmo em instituições. Além disso, o game é contentor de características e conhecimentos criados, aperfeiçoados, preservados e partilhados por um grupo de indivíduos, num intenso processo comunicacional capaz de conferir uma identidade ao mesmo tempo em que constitui um universo único, que pode gerar sentidos e significados que lhe são próprios. ZILLE (2012, p.8)

E em relação aos "gamers" podemos admitir que é possível identificar diversos tipos: o casual, o gamer regular, o profissional, o hardcore gamer, o retrogamer, import gamer, o cyber atleta e o gamer hacker.

\section{CULTURA GAMER}

Percebe-se a cultura gamer como heterogênea e múltipla, porém há um peso de criticidade quanto ao universo dos games, principalmente aos modos com os quais o ser humano pode utilizá-lo. Quando mencionamos em "universo dos games", geralmente as pessoas imaginam um universo paralelo ao qual existimos. Apesar de todas as imagens, backgrounds, efeitos sonoros, visuais e lúdicos, os games podem proporcionar uma ideia de irrealidade para 
alguns, mas para outros, o game é apenas uma ampliação da realidade, uma forma de ver o mundo do qual já existe.

\begin{abstract}
"Quem pensa que o virtual é outro mundo, precisa abrir os olhos e ver como ele também serve de novo veículo para a exploração econômica, a violência étnica, a manipulação política, a bestialidade humana e tudo o mais que nos enoja na vida real. O virtual e o real não são dois mundos paralelos: existem em relação dialética, o que significa dizer que entretêm relações de complementaridade, dependência recíproca e dinâmica tempestuosa que, em boa parte, podem ser examinadas à luz do conceito crítico de indústria cultural.” (RUDIGER, pág. 23, 2008)
\end{abstract}

Em nossa pesquisa de campo, por meio dos relatos dos comentários, desvendamos que a cultura gamer é ampla, diversificada, que vem se desenvolvendo bastante nos últimos anos e abrangendo cada vez mais diferentes faixas etárias e estilos de pessoas.

Na cultura gamer existem aquelas pessoas dedicadas e fanáticas por jogos, determinadas a serem as melhores de cada um dos seus jogos, essas são as mais competitivas, e outras são mais interativas e gostam de jogar para se divertir e fazer novas amizades.

Os comentários da pesquisa também revelaram que a cultura gamer em geral é fechada, machista, preconceituosa e excludente. Uma parcela significativa dos integrantes dessa cultura pode gerar discussões não saudáveis e agem com frequência de maneira opressora e assediadora. Assim, uma considerável parte dessa cultura vem se tornando tóxica, mas isso também acontece com internautas de modo geral. Segundo um dos comentários da pesquisa aquilo que percebemos em redes sociais, também acontecem em jogos multiplayers, desde construção de amizades e relacionamentos até inimizades e problemas na justiça. muito machista, fechada e exclusiva.

\title{
5.1 MACHISMOS
}

De acordo com o relato da entrevistada, quando mulheres geralmente vão jogar com seus nicknames femininos, logo são reconhecidas por seu gênero e os homens aproveitam para agredir verbalmente quando o time geralmente perde a partida (porque para eles o sexo feminino é sempre um sinal de "elo fraco"), mas principalmente são destratadas sob conotação sexual: xingamentos, convites para fazer sexo, apologia, solicitações, assédios variados e até mesmo envio de fotos pornográficas por parte dos próprios solicitantes e "colegas" gamers. 
Portanto, ultimamente, para se protegerem de tais atrocidades, as mulheres (incluindo a entrevistada) estão preferindo utilizar nicknames masculinos para não serem reconhecidas pelo seu gênero.

Figura 8 - Tomb Raider

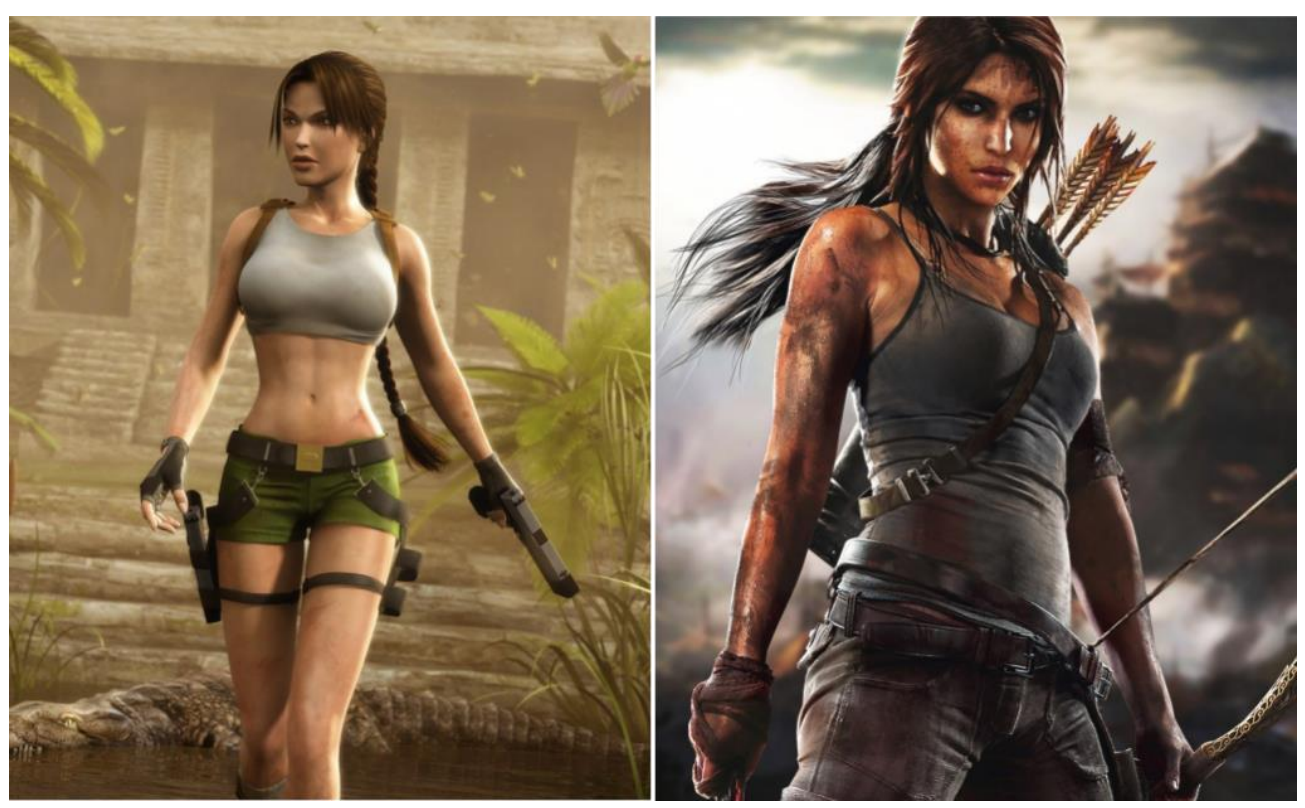

Fonte: Game Tomb Raider (2013)

Figura 9 - Street Fighter 


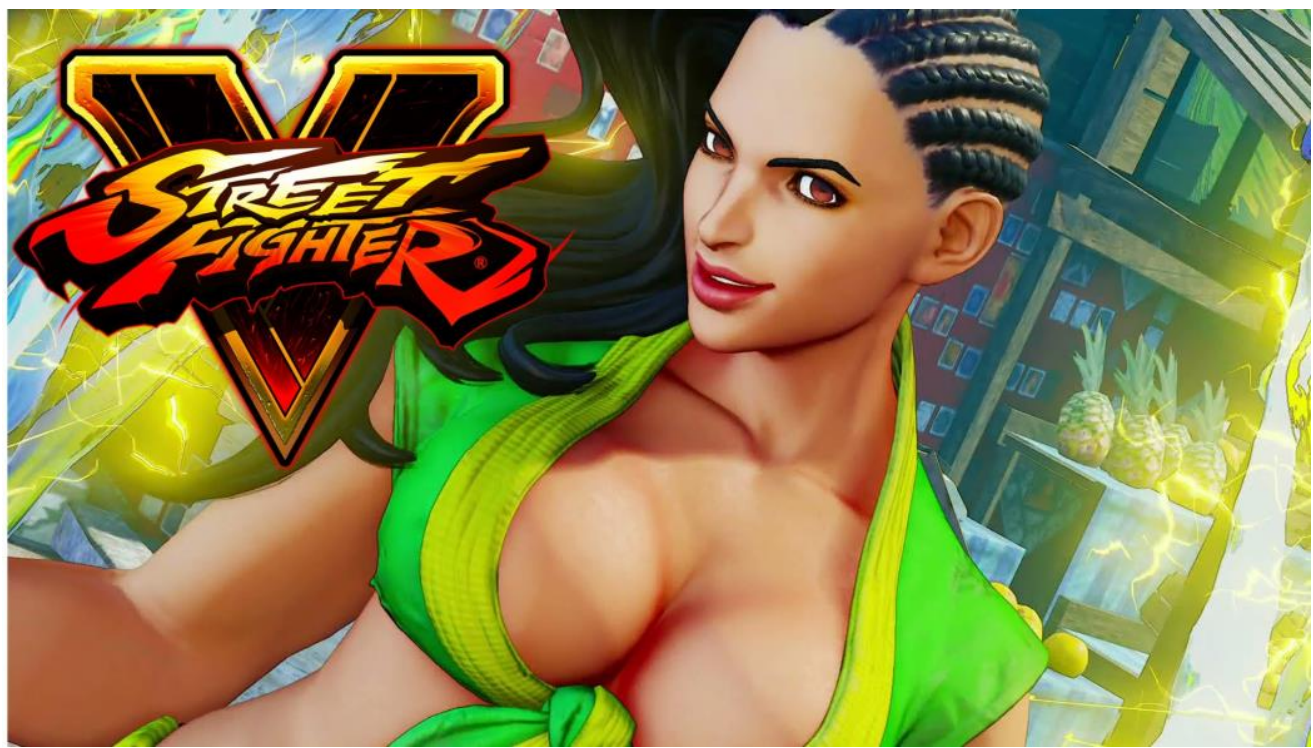

Fonte: Game Street Fighter V (2016)

De outro lado, há também a questão da objetificação visual da mulher dentro dos games. A própria indústria dos games utiliza a hiperssexualização como estratégia de marketing com o sentido de atrair especificamente "homens" para os jogos. Neste caso, os games são utilizados como uma interface para denotar a figura feminina (o "papel" da mulher dentro dos jogos) com nudez (ou seminudez), e corpo anguloso alinhado com os padrões de beleza atuais, referindo-se sempre à sexualidade. Transmite a ideia de que para ser uma gamer ou uma personagem nas narrativas gamers, você precisa se adequar a esses padrões para o jogo poder vender.

\subsection{AMBIENTE TÓXICO}

Outra problemática também relatada pela entrevistada e como resultado das respostas do formulário da pesquisa de campo, é que as pessoas usam o espaço dos games para camuflarem-se e desta forma, transforma-o num ambiente tóxico. Utilizam o espaço dos games para criar uma imagem ideal e fantasiosa da qual transmite uma pseudo valentia e a utilizam para a realidade e o convívio entre os gamers. O intuito de camuflarem-se é o de se protegerem por trás de uma "barricada" e desta forma poderem agredir ao próximo ilimitadamente (por assim dizer), crendo que nada poderá alcançá-lo.

Apesar de muitos jogos MOBA, como o League of Legends possuírem formas de reportar os assédios e variadas outras infrações dentro das regras dos games, ainda não é o suficiente para limitar ou fazer com que tais acontecimentos não ocorram. 
Dentro dos próprios chats dos games há relatos de ameaças, xingamentos, depreciação, stalkers, dependência, vícios. Mesmo os jogos também possuindo bloqueio automático de alguns termos nocivos, ainda não é suficiente, visto que por tal motivo há a necessidade e importância das empresas criadoras e moderadoras atualizarem-se linguisticamente quanto aos neologismos e gírias de diversificados países dos quais atuam mercadologicamente.

Figura 10 - Agressões Verbais

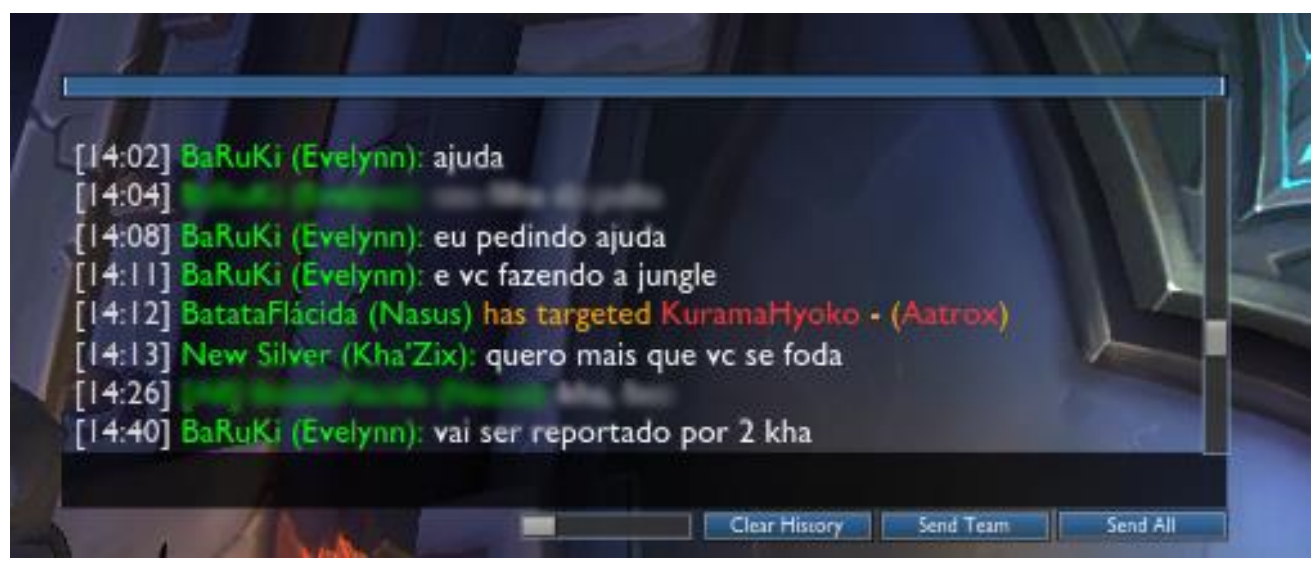

Fonte: Fórum do League of Legends (2013)

Há dentro desse contexto, também como resultantes e atuantes desse ambiente tóxico, os gamers que não separam as regras dos jogos e dos contextos narrativos com a realidade e que fogem de conceitos morais. São gamers que se imergem no universo gamer a ponto de não saberem mais lidar socialmente entre outros humanos. Geralmente adequam-se a um perfil de jogador que se aprofunda em jogos que são visualmente realistas em relação às ações que são consideradas imorais, como: jogos de terror; de ação; guerras; jogos que permitem visualizar os assassinatos que você reproduz dentro da narrativa; jogos sobre mercenários; jogos de luta e de violência gratuita; jogos que transmitem um nível extremo de adrenalina por também conterem contexto apocalípticos e casos entre vida ou morte (Counter Strike, Mortal Combat, Silent Hill, Little Nightmares, SOMA, Resident Evil, Dying Light, Layers of Fear).

\section{CONSIDERAÇÕES FINAIS}

De acordo com a presente pesquisa de campo, o fascínio pelo jogo motiva ao estudo informal do inglês e pode se dizer que os games, por sua intensa presença no mundo 
contemporâneo, ganha status de cultura e de identidade, que transmite e resulta numa linguagem gamer, além de fazer progredir o marketing gamer em empresas de tecnologias em games no mundo todo, atribuído-se a um perfil gamer.

Percebemos nesta pesquisa que para fazer parte dessa cultura é preciso inserir-se no universo gamer e aprender a lidar com os variados ambientes, aprender a língua inglesa e desenvolver habilidades de estratégia e lógica.

Os modos de aprendizagem do inglês e da própria linguagem dessa cultura tratam-se de uma política linguística não institucional, que provém de uma comunidade que apesar de ser fomentada por meio de acesso global, é excludente entre aqueles que não sabem lidar com a língua inglesa, que não possuem um perfil gamer e que não possuem ótimas habilidades para desenvolverem-se facilmente nos contextos narrativos dos games. Mostra-se, portanto, a conclusão de que as línguas são tendenciosas, como Silva (2013) explica: “As línguas não são neutras" e "estão envolvidas em agendas políticas, ideológicas, sociais e econômicas". Elas deliberadamente sofrem inputs e outputs, downloads e uploads de dados linguísticos conforme sua comunicação é exercida dentro deste ciberespaço cultural.

Sendo assim, os indivíduos dessa comunidade gamer são diferenciados em termos de identidade cultural tornando-se bilíngues biculturais.

Ainda é importante pontuar que existe uma forma não explícita de política linguística dentro da cultura gamer, pois esta por meio de sua linguagem artificial tem poder de influenciar e estimular comportamentos linguísticos e sociais através do perfil gamer ideal em que o marketing e a sociedade gamer fomentam.

Finalmente podemos assumir que a pesquisa comprovou que existe uma cultura que identificam os gamers e que dentro dela existem conflitos de identidade, de gênero e de ambientalidade.

\section{REFERÊNCIAS}

CARLSON, R.; CORLISS,J. Imagined Commodities: Video Game Localization and Mythologies of Cultural Difference. In:Games and Culture, vol. 6, 1: pp. 61-82. , First Published October 19, 2010.

CONDOMÍNIO SC. Quais são os principais polos tecnológicos do Brasil. Disponível em http://www.condominiosc.com.br/secoes/cidades/2613-quais-sao-os-principais-polos-

tecnologicos-do-brasil. Acesso em 06 de novembro de 2019.

HALL, Stuart. A identidade cultural na pós modernidade. $11^{\text {a }}$ ed. Rio de Janeiro: DP\&A, 2006. 102p. 
RUDIGER, F.R. Cibercultura e pós-humanismo: exercícios de arqueologia e criticismo. Porto Alegre: EDIPUCRS, 2008.

SANTAELlA, L. Games e Comunidades Virtuais. Disponível em http://www.canalcontemporaneo.art.br/tecnopoliticas/archives/000334.html. Acesso em 26 de outubro de 2019.

SCHUYTEMA, Paul. Design de games: uma abordagem prática. Tradução de Cláudia Mello Belhassof. São Paulo: Cengage Learning, 2008.

SEVEN IDIOMAS. 38 gírias que Todo Gamer Precisa Saber. Disponível em https://go.sevenidiomas.com.br/blog/28-girias-que-todo-gamer-precisa-saber/. Acesso em 29 de outubro de 2019.

SIGNIFICADOS. Significado de RPG. Disponível em: https://www.significados.com.br/rpg/. Acesso em 11 de dezembro de 2019.

SILVA, Elias Ribeiro da. A Pesquisa em Política Linguística - Histórico, Desenvolvimento e Pressupostos Epistemológicos. Disponível em: http://www.scielo.br/scielo.php?pid=S0103$\underline{18132013000200007 \& \text { script }=\text { sci } \_ \text {abstract\&tlng=es }}$

VALOR INVESTE. Brasil é o $13^{\circ}$ maior mercado de games do mundo e o maior da América Latina. Disponível em https://valorinveste.globo.com/objetivo/empreendase/noticia/2019/07/30/brasil-e-o-13o-maior-mercado-de-games-do-mundo-e-o-maior-daamerica-latina.ghtml. Acesso em 06 de novembro de 2019.

ZILLE, J.A.B. A intensificação do agenciamento nos games: do jogador ao jogadorcriador. Tese de Doutorado em comunicação e semiótica. PUC-SP, 2012. 